\title{
PROPOSTA DE IMPLEMENTAÇÃO DE ESTRATÉGIAS PARA GESTÃO ADMINISTRATIVA: ESTUDO DE CASO NA EMPRESA SC TRANSPORTES
}

\section{ARTIGO ORIGINAL}

SANTOS, Euler Ribeiro dos ${ }^{1}$, CORDEIRO, Izabele da Silva ${ }^{2}$, LIMA, Rita de Cássia Siqueira de ${ }^{3}$, ROBERTO, José Carlos Alves ${ }^{4}$

SANTOS, Euler Ribeiro dos. Et al. Proposta de implementação de estratégias para gestão administrativa: estudo de caso na empresa SC transportes. Revista Científica Multidisciplinar Núcleo do Conhecimento. Ano 06, Ed. 05, Vol. 04, pp. 16 40. Maio de 2021. ISSN: 2448-0959, Link de acesso: https://www.nucleodoconhecimento.com.br/administracao/empresa-sc-transportes, DOI: 10.32749/nucleodoconhecimento.com.br/administracao/empresa-sc-transportes

\section{RESUMO}

A busca pela excelência nos resultados frente à complexidade que envolve o mercado competitivo demanda por ferramentas estratégicas de comunicação e motivação que auxiliem não só a gestão administrativa das grandes empresas na propagação do modelo de gestão organizacional, como também na superação de metas. Neste artigo propõe-se a utilização das ferramentas supracitadas no âmbito da empresa SC Transportes em Manaus - AM, bem como a compreensão dos benefícios decorrentes

\footnotetext{
${ }^{1}$ Graduando do curso de administração.

${ }^{2}$ graduando do curso de administração.

${ }^{3}$ graduando do curso de administração.

${ }^{4}$ orientador. Mestrado profissional em engenharia de produção. Especialização em gestão em logística empresarial. Graduação em administração com ênfase em marketing.
}

RC: 84581

Disponível em: https://www.nucleodoconhecimento.com.br/administracao/empresa-sctransportes 
de sua implementação. Diante disso, os objetivos específicos traçados visam identificar as melhores práticas utilizadas na motivação e comunicação no âmbito interno das organizações, analisar quais dessas práticas se adequam na empresa estudada e, por fim, planejar ações para implementar as estratégias de gestão administrativa junto aos colaboradores. A metodologia utilizada baseou-se em aplicação de estudo de caso e embasamento por meio de pesquisa bibliográfica, configurando-se como quantitativa e qualitativa quanto a sua natureza, e exploratória e descritiva quanto ao seu objetivo. A proposição das ações interventivas se efetivou a partir da aplicação ferramenta da qualidade $5 \mathrm{~W} 2 \mathrm{H}$, dentre as quais se destacam: a implantação de ferramentas de comunicação interna e o plano de comunicação organizacional a ser elaborado, a implantação da gestão orientada para resultados como modelo de gestão organizacional, implementação de programas e planos de incentivos e bonificação por resultados. Assim, infere-se que, o plano proposto contribuirá decisivamente como referência no tratamento da problemática.

Palavras-Chave: Gestão administrativa, comunicação interna, motivação, resultados.

\section{INTRODUÇÃO}

Este artigo discorre na perspectiva de uma abordagem intervencionista no atual contexto da empresa SC Transportes, tendo por base a análise dos resultados provenientes da aplicação do diagnóstico organizacional, por meio do qual se permitiu identificar a gestão administrativa como o departamento mais deficitário dentre os demais, implicando na necessidade da implantação de melhorias que possibilitem a continuidade e retomada de crescimento do negócio, tornando a empresa mais competitiva no cenário em que atua.

Através da análise interna, verificou-se que, a reduzida comunicação organizacional interna e a baixa motivação dos colaboradores podem constituir elementos decisivos para o enfraquecimento do empreendimento no sentido de cumprimento de metas estabelecidas no seu planejamento estratégico, razão pela qual evidencia a

RC: 84581

Disponível em: https://www.nucleodoconhecimento.com.br/administracao/empresa-sctransportes 
importância de se traçar estratégias que garantam a fluidez da informação no ambiente corporativo, bem como a devolução aos colaboradores do sentimento de pertencer a organização, tendo em vista a possibilidade de garantir a eficiência e potencialização da produtividade.

O objetivo geral deste trabalho se firma na compreensão das vantagens que a adoção e a utilização de novas ferramentas estratégicas podem proporcionar à gestão organizacional. Para tanto, buscou-se as melhores práticas de enfrentamento ao problema identificado, com embasamento teórico dos diversos autores e destas escolheu-se as mais adequadas para aplicação na organização estudada. Em face do exposto foi realizado o planejamento de ações por meio da ferramenta $5 \mathrm{~W} 2 \mathrm{H}$ visando à implementação de estratégias de gestão administrativa junto aos colaboradores.

Este estudo se valeu do modelo de gestão iniciado por Peter Drucker, a gestão por resultados, como o indicado para a otimização do desempenho dos processos internos, tendo em vista maior objetividade, transparência e engajamento.

A tecnologia e a inovação permitem a utilização de diversas ferramentas de comunicação para diferentes níveis hierárquicos, nesse contexto foram sugeridas ferramentas que tornam o processo comunicacional mais eficiente, visando à interatividade entre os colaboradores e a acessibilidade às informações organizacionais. Os planos e programas de incentivo são apresentados como alternativas estratégicas relacionadas ao aumento da motivação, além de promover a retenção de talentos, melhor clima organizacional e impulsionar a lucratividade.

\section{REVISÃO BIBLIOGRÁFICA}

A revisão bibliográfica se utiliza do conhecimento científico acumulado de diversos autores ao longo do tempo e disponibilizado em suas obras publicadas, servindo de modelo teórico para explicar o fenômeno a ser estudado neste trabalho, buscando sua melhor compreensão através de conceitos chaves do assunto, além de identificar

RC: 84581

Disponível em: https://www.nucleodoconhecimento.com.br/administracao/empresa-sctransportes 
lacunas e contradições na busca pela estratégia de pesquisa, mostrando-se como parte essencial.

Silva (2014, p. 42) destaca que "o referencial teórico de uma pesquisa consiste na base conceitual que sustenta as argumentações do estudo. É construído a partir dos conceitos apresentados por diferentes autores."

Em face da literatura revisada se definirá uma análise crítica acerca da ciência da administração no âmbito da comunicação organizacional interna como elemento determinante na execução do planejamento estratégico, suas metas e objetivos definidos, destacando a relevância teórica e o elo com a hipótese formulada, operacionalizando conceitos que servirão de ligação ao nível empírico.

\subsection{CONCEITO DE PLANEJAMENTO ESTRATÉGICO}

A função administrativa de planejamento é vista como o elemento fundamental dos empreendimentos, posto que passa estabelecer um marco e uma direção que a empresa deverá seguir e como deverá agir frente aos resultados diferentes do planejado. Nesse sentido, dividem-se em missão, competências, valores e visão, cabendo ao planejamento operacional detalhar as ações que visam colocá-lo em prática. Dutra (2014, p. 80) considera o foco no futuro como característica importante no planejamento estratégico, e enfatiza "planejar significa conhecer o que existe e organizar métodos para integrar o real e se chegar ao ideal, ao foco, noutros termos, à Visão Organizacional."

O planejamento estratégico por se tratar do processo gerencial de maior amplitude dentro de uma organização serve como elemento norteador proativo em face dos cenários políticos, econômicos e competitivos, - envolve a tomada de decisão estratégica, buscando minimizar e impedir que as incertezas do ambiente externo possam impactar ou influenciar o desempenho da empresa, se valendo, para tanto, de uma visão sistêmica e holística.

RC: 84581

Disponível em: https://www.nucleodoconhecimento.com.br/administracao/empresa-sctransportes 
Essencialmente, o planejamento estratégico é um esforço disciplinado para produzir decisões e ações fundamentais que moldam e orientam o que é uma organização, o que ela faz e porque ela faz isso, inserindo-a no ambiente onde atua, com foco no futuro (CHIAVENATO e SAPIRO, 2020, p. 35).

Aquino (2016) pondera que o planejamento estratégico será efetivo se houver engajamento de todo o quadro de colaboradores, pois auxilia principalmente os níveis operacional e tático em aproximação com a administração estratégica, impulsionando a produtividade.

\subsubsection{GESTÃO ORIENTADA A METAS E RESULTADOS}

A Gestão voltada e orientada para metas e resultados constitui um sistema de gerenciamento ou metodologia alinhados aos objetivos estabelecidos em uma organização, a partir de sua definição e difusão no ambiente organizacional, cabendo a gestão propagar junto aos colaboradores a priorização nos resultados esperados a partir de metas periódicas e plano de recompensas, gerando no contexto, a motivação pela exploração de oportunidades.

Segundo Paludo (2016) para que esse modelo tenho o devido êxito, deve estar amparado por um sistema de informação gerencial visando avaliar os resultados alcançados, em constante comparação com planejamento estratégico estabelecido e indicadores gerenciais, e assim aplicar os ajustes necessários.

De acordo com Porpino e De Stefani (2014) a Gestão orientada a resultados é um processo sistemático capaz de comunicar aos constituintes até que ponto os objetivos e metas estabelecidas foram alcançados, tendo como resultados positivos o aumento da satisfação, a melhoria da autoestima dos empregados por meio da abertura do diálogo, com a possibilidade de maior retenção de colaboradores, somado ao fortalecimento da reputação institucional.

RC: 84581

Disponível em: https://www.nucleodoconhecimento.com.br/administracao/empresa-sctransportes 


\subsection{DEFINIÇÃO DE COMUNICAÇÃO ORGANIZACIONAL}

A comunicação organizacional, no Brasil também conhecida por comunicação empresarial ou corporativa, por ser um termo abrangente e de grande complexidade se traduz como "uma área interdisciplinar por definição que articula todas as estratégias de comunicação utilizadas pela organização no relacionamento e interação com seus públicos" (MELO, 2018, p. 9).

Kunsch (2012, p. 271) considera a dimensão estratégica da comunicação organizacional como a mais voltada aos resultados: "alinha-se, estrategicamente, por meio do planejamento e da gestão, aos objetivos globais da organização e aos princípios estabelecidos em relação a sua missão, sua visão e seus valores".

Para garantir seu posicionamento estratégico cabe às organizações a devida estruturação da comunicação nos âmbitos externo e interno. No contexto deste trabalho destaca-se a comunicação organizacional interna como o sistema de comunicação que trata seu público interno. Acredita-se que o processo de comunicação interna sustenta a comunicação externa, assim Matos (2014, p. 89) afirma que "consolidou-se no meio empresarial a importância da comunicação dentro da empresa, visando um maior engajamento e motivação dos funcionários para a consolidação dos objetivos e das metas da organização"

\subsubsection{CANAIS DE COMUNICAÇÃO INTERNA}

O canal de comunicação interna a ser utilizado deve considerar o porte da organização, o espaço entre sede e filiais, tipo de público e a frequência que a mensagem é enviada. Ressalta-se que as ferramentas tecnológicas são instrumentos dinâmicos, instantâneos e de baixo custo (SILVA, 2018).

Vide classificação a seguir:

- Periódicos: jornal, revista, boletim, folheto, tv interna, rádio.

RC: 84581

Disponível em: https://www.nucleodoconhecimento.com.br/administracao/empresa-sctransportes 
- Operacionais: intranet, telefone, quadro de avisos, correio eletrônico, manuais, relatórios, vídeos, videoconferências, conferências e seminários internos.

- Eventos: Integração, festas, esportes, cultura e educação.

- Programas de incentivo: concursos, premiações, caixas de sugestões e campanhas motivacionais.

\subsubsection{A COMUNICAÇÃO INTERNA COMO ESTRATÉGIA ORGANIZACIONAL}

Para que a comunicação organizacional obtenha o desempenho desejado frente ao mercado competitivo é necessário que se trabalhe de forma estratégica com envolvimento e compartilhamento de processos, informações e tecnologias.

Dessa forma, surge o conceito de comunicação organizacional integrada que Neves (2015, p. 87) define como "processo que integra todas as funções que se relacionam com públicos ou que fazem algum tipo de comunicação".

A partir da elaboração de um diagnóstico, inicia-se o planejamento e a aplicação do plano de comunicação. As etapas de gerenciamento dividem-se em divulgação do plano; sua implantação; o controle das ações executadas e a avaliação dos resultados.

Além disso, o plano de comunicação detalha os elementos necessários para se chegar objetivo de comunicação, devendo adequar-se às mudanças internas ou externas conforme a realidade da organização (NASCIMENTO, 2016).

De acordo com Melo (2018, p. 134) dentre as principais vantagens percebidas com a comunicação organizacional interna eficaz estão:

- Engaja os indivíduos, mas a partir de conteúdos solidamente plantados pela cultura organizacional.

RC: 84581

Disponível em: https://www.nucleodoconhecimento.com.br/administracao/empresa-sctransportes 
- Por integrar-se na coorientação, o funcionário é convocado a dialogar e a se perceber com agente de transformação na empresa e a se contextualizar.

- Em virtude desse processo de criação colaborativa e compartilhada de consciência(sensemaking), diminui-se a distância entre a organização e o funcionário.

\subsection{DEFINICÃO DE MOTIVAÇÃO}

A motivação é assunto constante no estudo do comportamento organizacional, visando explicar o entusiasmo ou a falta dele com o trabalho e seu impacto no ambiente organizacional, no cumprimento do planejamento estratégico, no sentido de otimizar o desempenho continuamente e obter resultados satisfatórios.

De forma geral, a motivação é definida como o interesse do colaborador pela ação, segundo Bergue (2014, p. 19) trata-se de "um impulso constante e de intensidade variável orientado para o alcance de um objetivo, seja este decorrente de uma necessidade ou de um estado de satisfação".

Outros autores a explicam a motivação como processo motivacional, em outras palavras, como sendo "o ato de encontrar motivos (pressão interna que surge a partir de uma necessidade) para agir, ou para desempenhar as atividades que nos foram atribuídas enquanto funcionários de uma organização" (OLBRZYMEK, 2017, p. 49).

Camacho (2016) argumenta que a motivação não deve ser confundida como uma característica da personalidade. De acordo com sua definição, trata-se de uma necessidade de incentivo, um processo psicológico inerente ao seu desempenho e comportamento em relação à determinada situação, por isso pode apresentar intensidades diferenciadas para cada indivíduo. 


\subsubsection{PROGRAMAS E PLANOS}

Ao assumir seu papel de destaque na gestão organizacional, a gestão de pessoas tem como principal missão impulsionar todos os colaboradores no cumprimento eficaz dos objetivos e metas planejados, dessa forma tem como premissa liderar e estabelecer políticas para a motivação frente ao trabalho. Nesse contexto faz-se necessário a elaboração de estratégias motivacionais que auxiliem nesse processo.

Denomina-se Processo de recompensa os sistemas de gestão de pessoas que visam ao incentivo e à motivação aos colaboradores através de reconhecimento, prêmio ou retribuição em virtude de seu desempenho aliando, dessa forma, a satisfação aos objetivos individuais, em relação ao alcance dos objetivos organizacionais, colaborando para o engajamento e permanência na empresa (CHIAVENATO, 2014).

De acordo com Dambi (2018, p. 108) a partir de estudos realizados os "programas de incentivos e os sistemas de recompensas, funcionam como motivadores e incentivam a participação dos funcionários na prossecução dos objetivos da organização", sendo determinantes para a performance dos colaboradores e competividade.

\subsection{GESTÃO DE PESSOAS}

Fator de grande relevância no contexto organizacional, a Gestão de pessoas, numa visão contemporânea está relacionado ao potencial de mobilizar os colaboradores para alcanças os resultados, ou seja, o estabelecimento de estratégias organizacionais que agreguem ao objetivo global da empresa. De acordo com a definição de Dutra (2014, p. 10) a Gestão de pessoas é entendida como sendo um "ramo interdisciplinar que aborda a Psicologia Organizacional e do Trabalho e que contempla todas as ações empreendidas por uma organização, com o objetivo de integrar o colaborador no contexto da organização e aumentar sua produtividade". 
Considerando que a sintonia entre gestão de pessoas e nível estratégico da organização são essenciais para seu desempenho, a estruturação de estratégias de comprometimento torna-se um diferencial competitivo. Pois, a inserção de pessoas agrega valor ao processo participativo, segundo o qual comprometimento e aumento de desempenho são intimamente relacionados (DREWS et al, 2012).

\subsubsection{CAPACITAÇÃO E DESENVOLVIMENTO DE PESSOAL}

A função que compreende a capacitação e o desenvolvimento de colaboradores é uma ação de caráter estratégico dentro das organizações que visa qualificar sistematicamente seu quadro de pessoal para representar diferencial competitivo frente aos concorrentes com melhor desempenho e potencializar as competências e os resultados através de investimentos em capital humano (CANABRAVA e VIEIRA, 2014).

Embora utilizadas juntas, capacitação ou treinamento e desenvolvimento possuem conceitos diferentes:

O desenvolvimento profissional é o tipo de educação profissional que visa o aperfeiçoamento, ou seja, o encarreiramento em determinada profissão. Tem o objetivo de desenvolvimento de desenvolver a pessoa para seu crescimento profissional em determinada carreira na organização ou para que se torne mais eficiente e produtivo no seu cargo. [...]

O treinamento é educação profissional que adapta a pessoa para um cargo ou uma função. Seus objetivos são restritos e imediatos, situados no curto prazo, oferecendo os elementos essenciais para o exercício de um cargo e preparando adequadamente para esse cargo. É promovido na própria empresa ou por empresas especializadas em treinamento e pode ser aplicada a todos níveis e setores da empresa. [...] (LANGHI, 2019, p. 11).

\subsection{CULTURA ORGANIZACIONAL}

Os diversos conceitos que buscam explicar a cultura organizacional a consideram como sistemas organizacionais que partem da mentalidade do fundador ou de uma

RC: 84581

Disponível em: https://www.nucleodoconhecimento.com.br/administracao/empresa-sctransportes 
liderança da gestão, de modo a resultar no comportamento organizacional e consequências advindas deste. Camacho (2016, p. 28) define a cultura organizacional como "o conjunto de hábitos e crenças estabelecidos por meio de normas, valores, atitudes e expectativas compartilhados por todos os membros da organização, e é isto o que distingue uma organização das demais".

O ambiente interno pode ter uma cultura dominante ou traços de diversas culturas organizacionais distintas. Dentre as características que compõem a cultura organizacional, ressalta-se a orientação aos resultados, em virtude do grau em que se almeja alcançá-los (OLBRZYMEK, 2017).

A cultura organizacional se estabelece simbolicamente como propagadora dos valores em face as transformações culturais recorrentes na sociedade contemporânea, no que a tange o papel como elemento da comunicação organizacional pode-se ressaltar o entendimento dos aspectos culturais como dados que podem ser interpretados e revertidos a favor da organização como informações estratégicas, desse forma o processo comunicacional se mostra como o reflexo da sua cultura organizacional (SILVA, 2018).

\subsubsection{CLIMA ORGANIZACIONAL}

O clima organizacional, atributo que sofre forte influência da cultura organizacional, determina a satisfação dos colaboradores ao fazer parte da organização, fator importante no grau de motivação ao executar as tarefas, nas relações interpessoais de trabalho e com a própria empresa.

Segundo Chiavenato (2014) o conceito de clima organizacional surgiu para descrever as relações sociais que dominam a organização, bem como a conduta, sensações e o entendimento para com estas. Elementos como o envolvimento do funcionário aos arranjos, processos e práticas organizacionais tem influência importante no desdobramento das interações provenientes das relações sociais. Acredita-se na

RC: 84581

Disponível em: https://www.nucleodoconhecimento.com.br/administracao/empresa-sctransportes 
verificação do clima organizacional como aspecto relevante na ampliação da eficiência e da motivação em razão da conquista de resultados, tendo como ferramentas as pesquisas de clima. Considera-se o campo psicológico no âmbito motivacional dos colaboradores e seu ambiente de trabalho de suma importância para o contexto do clima organizacional. Por meio das pesquisas de clima é possível coletar informações dos colaboradores e mensurar a partir desses dados o contentamento nas relações de trabalho.

\section{MATERIAIS E MÉTODOS}

A metodologia científica surge com a definição da problemática e apresenta-se como o conjunto de processos e técnicas aplicados a partir de atividades sistemáticas e racionais que levarão a construção de um resultado científico.

De acordo com Pereira et al. (2018, p. 27) "o método científico parte da observação organizada de fatos, da realização de experiências, das deduções lógicas e da comprovação científica dos resultados obtidos."

\subsection{PROCEDIMENTOS METODOLÓGICOS}

Os procedimentos metodológicos são compostos por técnicas que consolidam os métodos escolhidos para a realização do trabalho de pesquisa. Zanella (2013) destaca que um tipo de pesquisa não exclui o outro, devendo as metodologias de pesquisa ser complementares entre si.

Nesse contexto a coleta de dados é a parte prática da pesquisa, razão pela qual, o detalhamento de seus instrumentos e programação serão explorados a seguir.

\subsubsection{QUANTO A NATUREZA}

No que tange à natureza deste trabalho, classifica-se como pesquisa quantitativa e qualitativa. A pesquisa quantitativa busca compreender a realidade através dos dados

RC: 84581

Disponível em: https://www.nucleodoconhecimento.com.br/administracao/empresa-sctransportes 
numéricos, coletados para fins estatísticos e vistos de maneira mais objetiva. Por outro lado, a pesquisa qualitativa visa mostrar uma realidade por meio da verbalização, permitindo-se assim uma interpretação reflexiva dos dados.

Silva (2014, p. 20) enfatiza esta metodologia:

Primeiramente é conduzida a fase qualitativa para se conhecer o fenômeno estudado. De posse dessas informações, parte-se para a construção de um questionário fechado e o aplica no setor. Depois da tabulação, é feita a análise dos dados com o auxílio de instrumentos estatísticos.

\subsubsection{QUANTOS AOS FINS}

Quanto ao seu objetivo, esta pesquisa caracteriza-se como exploratória, em que se busca-se um ampliar os conhecimentos sobre determinado fenômeno, e descritiva, no sentido de mostrar com exatidão os fatos da realidade verificada.

De acordo com a estratégia adotada ao objetivo, Zanella (2013) destaca que a pesquisa exploratória investiga para maior conhecimento e posteriormente executarse a pesquisa descritiva, complementando-se.

\subsubsection{QUANTOS AOS MEIOS}

Os procedimentos adotados para a coleta dos dados classificam-se como pesquisa bibliográfica, a partir de publicações da comunidade acadêmica científica, tais como livros, artigos e periódicos, e estudo de caso, permitindo-se obter conhecimentos mais aprofundados sobre a organização estudada por meio da análise dos resultados.

Para Pereira (2018) o estudo de caso "pode trazer uma riqueza de dados e informações de modo a contribuir com o saber na área de conhecimentos na qual for utilizada". 


\subsection{CARACTERÍSTICAS DA EMPRESA}

A Socorro Carvalho Transportes LTDA. é uma empresa amazônica, fundada em 1976, atualmente sendo considerada uma empresa de porte médio. Está sediada em Manaus, na Avenida Djalma Batista, número 1719, bairro Chapada, com filiais em Belém e Porto Velho. Oferece serviços de transporte aquaviário nos ramos de: Combustíveis, Carga Geral, Projetos, Embarcações, Máquinas e Equipamentos.

A empresa nasceu da necessidade de profissionalizar as atividades de transporte de combustíveis no interior. E estendeu-se, em seguida, para novas rotas, com investimentos em tecnologia e inovação para suas embarcações e equipamentos, e no treinamento de seus funcionários. Ela ocupa uma posição de destaque no mercado local, tendo como clientes grandes empresas nacionais. Nesse aspecto, para sua expansão no cenário local e nacional, a empresa necessita de ampliação de pessoal, com colaboradores que trabalhem de acordo com as metas estabelecidas, cumprindo o propósito organizacional e possibilitando aumento contínuo dos lucros.

\section{RESULTADOS E DISCUSSÕES}

A coleta de dados se deu com a aplicação de questionários e entrevistas orais aos gestores, observações nas atividades do cotidiano da empresa e verificação de relatórios gerenciais.

As informações coletadas na fase inicial possibilitaram a elaboração do Diagnóstico Organizacional, reunindo dados pertinentes a cada departamento da organização em estudo. O Gráfico 01: Desempenho por área funcional, ao qual permite a visualização e o comparativo destes elementos.

RC: 84581

Disponível em: https://www.nucleodoconhecimento.com.br/administracao/empresa-sctransportes 
Gráfico 1 - Desempenho por área funcional

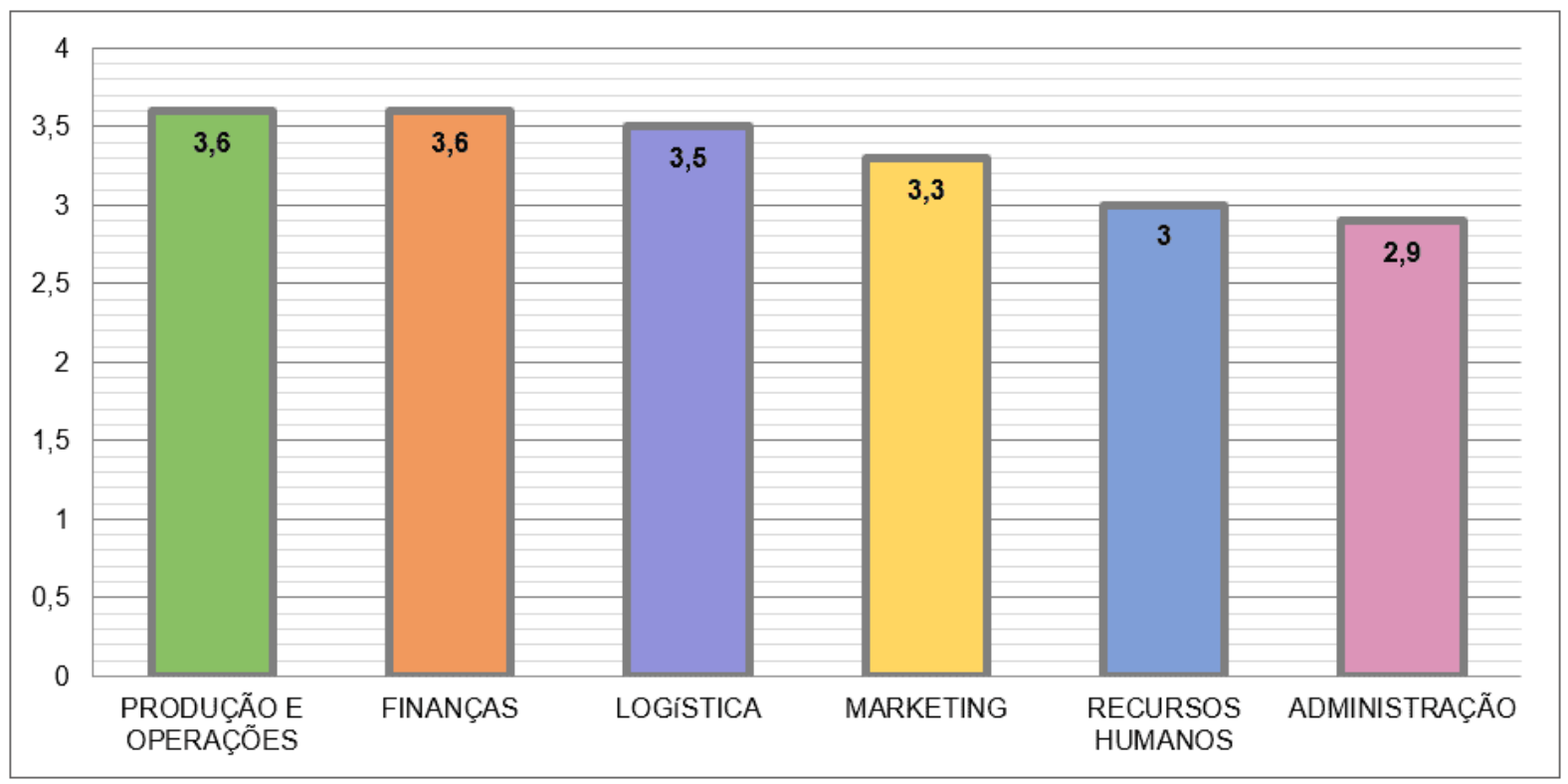

Fonte: Elaborado pelos autores com base em pesquisa de campo (2020)

O gráfico acima foi elaborado a partir da aplicação de questionários e entrevistas orais junto aos gestores de cada área funcional que constitui a gestão organizacional da empresa SC Transportes, totalizando 10 fatores críticos analisados em cada departamento, com pontuações atribuídas com valores que variam entre 1,0 (ponto muito fraco) a 5,0 (ponto muito forte).

Dessa forma, o somatório das pontuações obtidas possibilitou o cálculo da média de cada setor e, por fim, a comparação quantitativa entre eles. Além disso, em cada departamento foi verificado in-loco, por meio de observações dos autores a procedência das informações analisadas, levando-se em conta a análise de informações constantes dos relatórios do Sistema de Gestão Integrada da organização.

A partir do contexto apresentado graficamente, pode-se determinar os departamentos de Produção e Operações, e Finanças, respectivamente, como melhores desempenhos; Logística e Marketing com performance mediana.

RC: 84581

Disponível em: https://www.nucleodoconhecimento.com.br/administracao/empresa-sctransportes 
No entanto, as áreas de Recursos Humanos e Administração apresentam-se como menos satisfatórias e demandam por maior intervenção, sendo a gestão administrativa evidenciada como área mais crítica, vide Quadro 1, necessitando de soluções mais urgentes para a melhoria do negócio e continuidade do empreendimento.

\section{Quadro 1 - ADMINISTRAÇÃO}

\begin{tabular}{|c|c|c|c|c|c|c|}
\hline \multicolumn{2}{|r|}{ ÁREA FUNCIONAL: ADMINISTRAÇÃO } & \multicolumn{5}{|c|}{ NÍVEL OU GRAU DEAVALAÇÃO } \\
\hline \multicolumn{2}{|r|}{ Fatores Críticos } & $\begin{array}{l}\text { Ponto } \\
\text { m uito }\end{array}$ & $\begin{array}{l}\text { Ponto } \\
\text { forte }\end{array}$ & $\begin{array}{l}\text { Ponto } \\
\text { m édio }\end{array}$ & \begin{tabular}{|l|} 
Ponto \\
fraco
\end{tabular} & $\begin{array}{l}\text { Ponto } \\
\text { m uito }\end{array}$ \\
\hline 1 & A empresa possui objetivos e metas declaradas & $\mathrm{x}$ & & & & \\
\hline 2 & Todos os colaboradores conhecem os objetivos e metas da organização & & & & & $\mathrm{x}$ \\
\hline 3 & A equipe de colaboradores é engajada na execução das metas & & & & $\mathrm{x}$ & \\
\hline 4 & A empresa possui habilidades, competências e experiência no ramo reconhecidas pelo mercado & & $\mathrm{x}$ & & & \\
\hline 5 & Existe coordenação de esforços para atingir as metas da organização & & & $\mathrm{x}$ & & \\
\hline 6 & Processo decisório da organização é simples e transparente, tornando a em presa ágil & & $\mathrm{x}$ & & & \\
\hline 7 & Os benefícios oferecidos pela empresa contribuem para motivação dos colaboradores & & & & $\mathrm{x}$ & \\
\hline 8 & A empresa possui algum tipo de "bônus financeiro" por atingimento ou superação de metas & & & & & $\mathrm{x}$ \\
\hline 9 & Os colaboradores tem o respeito profissional pela equipe de gestão & & $\mathrm{x}$ & & & \\
\hline 10 & A empresa possui processos de gestão estruturados e declarados & & & $\mathrm{x}$ & & \\
\hline & TOTAL $(\Sigma)$ & 5 & 12 & 6 & 4 & 2 \\
\hline & MÉDIAPOR GRAU & 0,5 & 1,2 & 0,6 & 0,4 & 0,2 \\
\hline & DESEMPENHO DAÁREA $(\Sigma)$ & & & 2,9 & & \\
\hline
\end{tabular}

Fonte: Elaborado pelos autores com base em pesquisa de campo (2020)

No quadro acima são apresentados os 10 fatores críticos de maior relevância, pesquisados no âmbito da gestão administrativa, da mesma forma aplicada a cada setor. Para cada fator foi feita a atribuição de pontuações de acordo com as situações analisadas.

Desta forma, pode-se verificar que os fatores 2, 3, 5, 7, 8 e 10 são determinantes para se apontar a gestão administrativa como o setor mais deficitário, haja visto o desempenho com notas de nível médio a muito fraco, resultando na pontuação da média 2,9.

RC: 84581

Disponível em: https://www.nucleodoconhecimento.com.br/administracao/empresa-sctransportes 
Os fatores críticos analisados na empresa SC Transportes constantes no quadro acima, se destacam como de fundamental relevância na gestão organizacional, razão pela qual indica a necessidade de comunicação eficiente e motivação junto aos colaboradores, propagando metas e objetivos e promovendo engajamento e comprometimento no alcance do propósito organizacional.

Levando em consideração esses aspectos, chega-se a seguinte problemática: Como a empresa SC Transportes pode beneficiar-se com vantagem competitiva por meio de implementação de novas estratégias para a gestão administrativa?

\subsection{PLANEJAMENTO DE AÇÕES}

Esta etapa estabelece o planejamento das ações estratégicas necessárias para o enfrentamento do problema, com a enumeração das etapas do processo pretendido para se obter de forma assertiva o objetivo.

Para tanto é realizado o detalhamento das atividades sequenciais, que de forma conjunta se complementarão, assim como a estimativa de períodos e custos por meio de cronograma.

Quadro 2 - Ações interventivas

\begin{tabular}{|l|l|l|l|l|}
\hline ITEM & AÇÕES INTERVENTIVAS & CRONOLOGIA & DURAÇÃO & CUSTO \\
\hline 01 & $\begin{array}{l}\text { Desenvolver gestão de metas } \\
\text { organizacionais. }\end{array}$ & Abril/ 2021 & 30 dias & - \\
\hline 02 & $\begin{array}{l}\text { Estruturar plano de } \\
\text { capacitação e desenvolvimento } \\
\text { de colaboradores. }\end{array}$ & Abril/ 2021 & Anual & $\mathrm{R} \$$ \\
\hline 03 & $\begin{array}{l}\text { Estruturar plano de } \\
\text { comunicação interna. }\end{array}$ & Abril//2021 & $227.968,00$ \\
\hline
\end{tabular}

RC: 84581

Disponível em: https://www.nucleodoconhecimento.com.br/administracao/empresa-sctransportes 


\begin{tabular}{|l|l|l|l|l|}
\hline 04 & $\begin{array}{l}\text { Implantar ferramentas de } \\
\text { comunicação interna (portal e } \\
\text { aplicativo corporativos). }\end{array}$ & Abril/ 2021 dias & $\mathrm{R} \$$ \\
\hline $05 \quad \begin{array}{l}\text { Implementar programa de } \\
\text { incentivos (com mensuração } \\
\text { constante) e bonificação por } \\
\text { resultados. }\end{array}$ & $36.000,00$ \\
\hline TOTAL & dias & $\mathrm{R} \$$ \\
\hline
\end{tabular}

Fonte: Elaborado pelos autores (2021)

O quadro 2 destaca cada ação com objetivo sanar os fatores críticos com pontuação mediana a muito fraca, identificados na investigação de desempenho da gestão administrativa, com estimativas e custos de acordo com pesquisa de mercado feitas pelos autores. A ordem lógica destas ações pode ser visualizada no fluxograma do processo, a ser apresentado no final deste trabalho.

A ferramenta $5 \mathrm{~W} 2 \mathrm{H}$ destaca-se por sua usabilidade em diversos segmentos, delineando através de perguntas a resolução sistemática de diferentes problemáticas. Desse modo, serviu como instrumento de aplicação das ações propostas na abordagem. $\mathrm{O}$ detalhamento de cada ação se dá nos tópicos a seguir.

\subsubsection{DESENVOLVER GESTÃO DE METAS ORGANIZACIONAIS}

Direcionar a cultura organizacional para metas ou resultados consiste na utilização de metodologias e comportamentos sistematizados em torno do objetivo da empresa e para isso devem estar constantemente no ambiente de trabalho. Esse objetivo se desenvolverá por meio da documentação das ações e divulgação junto aos colaboradores, transformando estratégias organizacionais em metas, buscando a participação e adesão em torno do compromisso com a nova ideia.

RC: 84581

Disponível em: https://www.nucleodoconhecimento.com.br/administracao/empresa-sctransportes 
Quadro 5-5W2H - Desenvolver gestão de metas organizacionais

\section{Desenvolver gestão de metas organizacionais}

O que? Documentar e aplicar uma cultura de foco em resultados.

Por quê? Para direcionar os trabalhos à produtividade e metas organizacionais.

Onde? Na empresa SC Transportes

Quando? Na primeira semana de abril de 2021

Quem? Gestão administrativa da SC Transportes

Como? Elaboração e divulgação de documento com as políticas estabelecidas.

Quanto? Nenhum custo.

Fonte: Elaborado pelos autores (2021)

O quadro 5 detalha o plano de gestão orientado a metas e resultados como a premissa para todas as ações planejadas, visto que este possui a função de estabelecer as diretrizes documentais que orientarão a nova cultura organizacional, bem como a maneira que estas serão implementadas em conjunto com todos os departamentos. Assim, em face dessa situação, acredita-se que, o prazo de uma semana, seja o suficiente para sua implantação e divulgação junto aos colaboradores, levando-se em consideração o período de adaptação.

\subsubsection{ESTRUTURAR PLANO DE CAPACITAÇÃO E DESENVOLVIMENTO DE COLABORADORES}

O plano de capacitação e desenvolvimento tem como objetivo a melhoria contínua das competências organizacionais, agregando valor aos colaboradores, aos serviços oferecidos e à imagem da própria empresa. E com a aquisição de novos conhecimentos e habilidades, surge a possibilidade de produzir um melhor desempenho profissional, aprimoramento técnico, alinhamento com a cultura organizacional, refletindo na melhoria do clima organizacional, identificação de 
lideranças e eliminação de ruídos na comunicação, culminando, desse modo, no aumento da produtividade.

Quadro 4 - 5W2H - Estruturar plano de capacitação e desenvolvimento de colaboradores

\section{Estruturar plano de capacitação e desenvolvimento de colaboradores}

O que? Capacitar e desenvolver os colaboradores

Por quê? Para impulsionar motivação e engajamento com a organização.

Onde? Na sede da empresa SC Transportes.

Quando? Mensalmente, no período de um ano.

Quem? Gestão de recursos humanos.

Como? Contratando empresa especializada em cursos de reciclagem.

Quanto? $\mathrm{R} \$ 227.968,00$

Fonte: Elaborado pelos autores (2021)

O quadro 4 acima, evidencia o plano de capacitação e desenvolvimento a ser disponibilizado juntos aos colaboradores. Esta ação apresenta apenas o orçamento do plano de capacitação, considerando que este se objetiva de abranger todo o quantitativo de funcionários no desempenho de suas funções técnicas, podendo o custo decorrente ser pago mensalmente pela empresa.

Assim, tendo em vista que o plano de desenvolvimento deve ser elaborado de acordo com a visão de futuro profissional de cada colaborador, este deve ser desenvolvido posteriormente. E quanto ao estabelecimento dos méritos para o alcance desse benefício, é certo que deve estar atrelado ao modelo de gestão de resultados em sintonia com a gestão de recursos humanos da organização. 


\subsubsection{ESTRUTURAR PLANO DE COMUNICAÇÃO INTERNA}

O plano de comunicação interna visa definir processos de gestão, assim como também, elaborar diretrizes para a comunicação interna e canais de comunicação a serem utilizados no âmbito corporativo com o objetivo de integrar os colaboradores, alinhá-los aos objetivos e estratégias da gestão organizacional. Como benefícios para cultura organizacional pode-se citar o sentimento de pertencimento e a motivação, refletindo em bom clima organizacional e imagem positiva da empresa.

Quadro 7 - 5W2H - Estruturar plano de comunicação interna

\section{Estruturar plano de comunicação interna}

O que? Plano de comunicação interna

Por quê? Definir os processos de gestão e estabelecer diretrizes de comunicação interna na cultura organizacional.

Onde? Na empresa SC Transportes

Quando? No mês de abril de 2021

Quem? Por meio da contratação de empresa de consultoria

Como? Elaboração de estratégias de comunicação na cultura organizacional

Quanto? R\$1.500,00

Fonte: Elaborado pelos autores (2021)

O quadro 7 acima, enfatiza o detalhamento da estruturação do plano de comunicação a ser desenvolvido. Seu objetivo é definir todas as diretrizes relacionadas ao processo de comunicação interna no âmbito do ambiente de trabalho englobando todos os níveis hierárquicos. Este plano deve ser elaborado a partir de consultoria externa por uma empresa especializada em parceria com a gestão organizacional. Quanto ao custo, este foi definido com base no valor de mercado pesquisado pelos autores. 


\subsubsection{IMPLANTAR FERRAMENTAS DE COMUNICAÇÃO INTERNA}

Para que o planejamento estratégico da organização apresente o maior êxito possível é necessário principalmente que ele esteja amparado em uma boa estratégia de comunicação. Nesse aspecto, a plataforma de informação requer estrutura profissional, valendo-se de diferentes canais de comunicação como site e aplicativo corporativos e adotando meios tradicionais também. Desse modo, organização precisa disponibilizar recursos para soluções eficientes tendo à frente profissionais experientes e qualificados, que tendem a fortalecer, em longo prazo o problema da comunicação em todos os níveis.

Quadro 3 - 5W2H - Implantar ferramentas de comunicação interna

\section{Implantar ferramentas de comunicação interna}

O que? Desenvolvimento e disponibilização de portal e aplicativo corporativos.

Por quê? Para conhecimento do planejamento estratégico de forma prática e rápida.

Onde? Acesso em computadores, tablets e smartphones.

Quando? Primeira semana de abril de 2021

Quem? Todos os colaboradores da SC Transportes

Como? Desenvolvido por empresa especializada

Quanto? Portal $R \$ 6.000,00$ + Aplicativo $R \$ 30.000,00=$ Total $R \$ 36.000,00$

Fonte: Elaborado pelos autores (2021)

O quadro 3 acima, apresenta a implantação de ferramentas de comunicação interna, as quais visam promover a integração e a interatividade por meio de ferramentas eficazes baseadas em tecnologia e inovação como portal e aplicativo corporativos. $O$ prazo estabelecido considerará a instalação e a adaptação inicial dos colaboradores com as respectivas ferramentas, cabendo a empresa desenvolvedora fazer as otimizações necessárias para seu melhor desempenho. Esta ação está atrelada ao

RC: 84581

Disponível em: https://www.nucleodoconhecimento.com.br/administracao/empresa-sctransportes 
plano de comunicação interna, que visa estabelecer as diretrizes para a utilização das mesmas no ambiente organizacional.

\subsubsection{IMPLEMENTAR PROGRAMAS DE INCENTIVOS E BONIFICAÇÃO POR RESULTADOS}

A estratégia para aumentar a produtividade e a motivação nos colaboradores consiste na sistematização de programa de incentivos a partir de premiações como passeios e brindes, a serem concedidos conforme o destaque em relação a aspectos positivos no âmbito das atividades organizacionais de cada departamento. Além do mais, vale ressaltar que a adoção do plano de bonificação por resultados visa a criação de políticas de concessão de incentivos financeiros pela superação das metas estipuladas no planejamento estratégico.

Nesse sentido, a gestão de pessoas torna-se fortalecida com essas ações, já que pode favorecer e impulsionar, ao mesmo tempo, o engajamento e comprometimento nos colaboradores. Tais medidas podem contribuir positivamente para a cultura e clima organizacionais, promovendo um ambiente competitivo e a retenção de talentos, além de crescimento nos lucros.

Quadro 6-5W2H - Implementar programa de incentivos

\section{Implementar programa de incentivos}

\begin{tabular}{|l|l|}
\hline O que? & Programa de incentivos e bonificação financeira por resultados \\
\hline Por quê? & Para elevar a motivação no alcance de metas. \\
\hline $\begin{array}{l}\text { Onde? } \\
\text { Quando? }\end{array}$ & Ma empresa SC Transportes \\
\hline Quem? & $\begin{array}{l}\text { Todos os colaboradores (bonificação apenas os que alcançarem as } \\
\text { metas). }\end{array}$ \\
\hline
\end{tabular}


Como? Contemplando os colaboradores destaque com premiações. A bonificação financeira a ser recebida junto ao salário de acordo com as metas alcançadas no plano de gestão de resultados.

Quanto? R $\$ 10.000,00$

Fonte: Elaborado pelos autores (2021)

O quadro 6 acima, agrega os programas de incentivo e bonificação financeira a ser disponibilizados. É importante observar que tratam de programas diferentes. E embora apresentem finalidade motivacional, devem ser disponibilizados ao final de cada mês, observando-se também que o valor sugerido pode sofrer alterações conforme as políticas definidas nos respectivos programas.

A ideia do programa de incentivos é oferecer brindes aos colaboradores que venham a se destacar nos aspectos qualitativos das atividades desenvolvidas no ambiente de trabalho de cada setor. Além do mais, o pagamento decorrente do programa de bonificação financeira deve ser incluído junto ao salário mensal, podendo ser pago conforme alcance de metas quantitativas de maneira individual ou coletiva, de acordo com os critérios a serem estabelecidos na gestão de resultados e metas.

\subsection{FLUXOGRAMA DA MELHORIA PROPOSTA}

Diante da análise realizada no departamento de administração da SC Transportes, foi elaborado um modelo de fluxograma, por meio do qual procura-se definir o fluxo das atividades do processo, permitindo uma visualização de maneira ampla e intuitiva acerca da deficiência na comunicação interna e motivação dos colaboradores, facilitando, assim, para o entendimento e direcionamento das ações propostas e suas interações para se chegar à solução ou cenário ideal.

RC: 84581

Disponível em: https://www.nucleodoconhecimento.com.br/administracao/empresa-sctransportes 
Figura 1 - Fluxograma da melhoria proposta

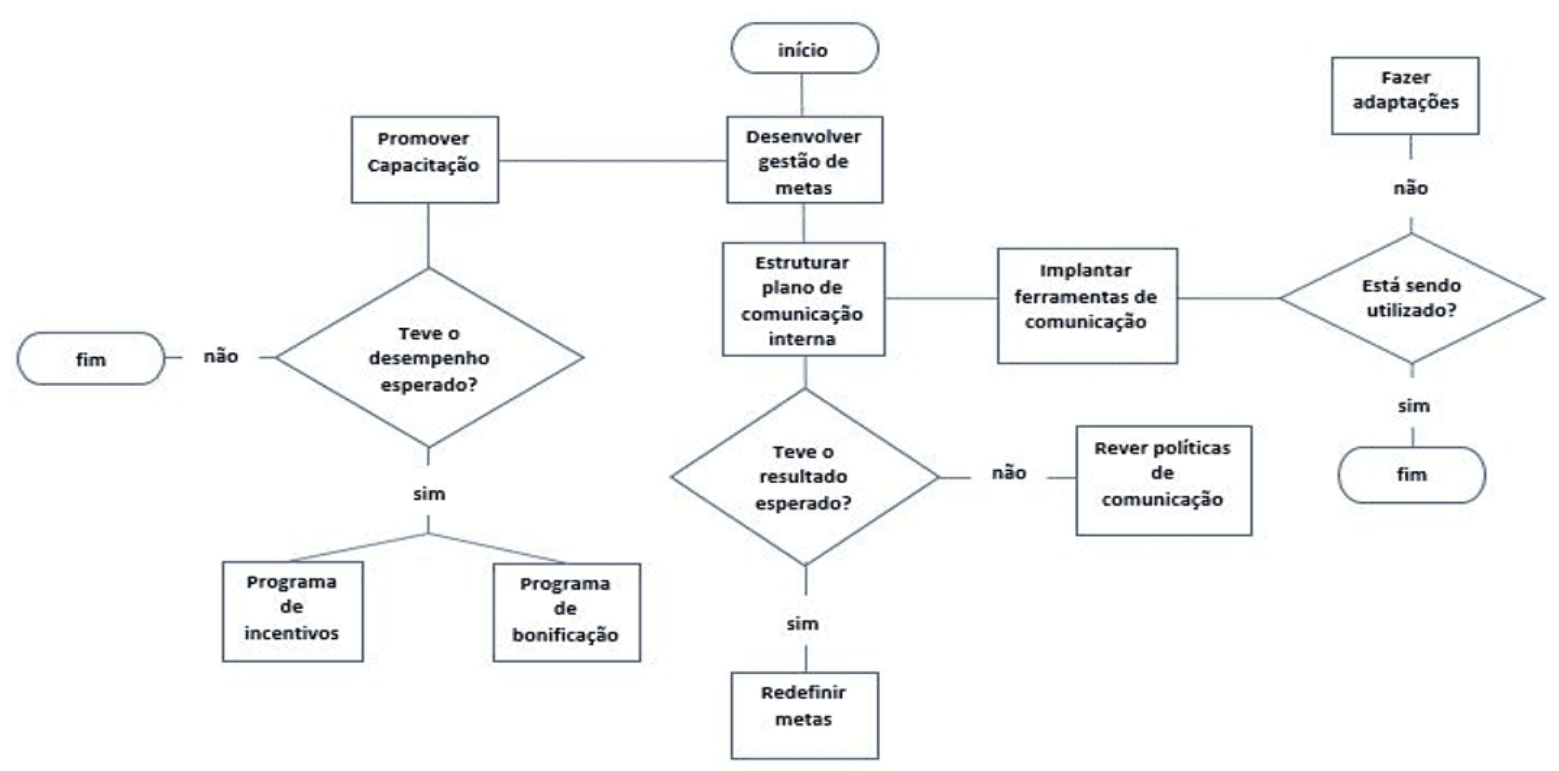

Fonte: Elaborado pelos autores (2021)

A figura 1 acima mostra a sequência de ações estratégicas do processo de melhoria proposto no plano de ações já abordado. O processo se inicia com a implantação da gestão orientada para as metas e aos resultados como modelo de gestão e prossegue com a adoção do programa de capacitação e desenvolvimento dos colaboradores, e de acordo com o desempenho destes a concessão aos programas de incentivos e bonificação financeira. Posteriormente, estrutura-se o plano de comunicação interna; e, implantam-se as ferramentas de comunicação interna. Por fim, é importante salientar que, os resultados devem ser avaliados continuamente conforme sugere 0 processo.

\section{CONSIDERAÇÕES FINAIS}

Este trabalho surgiu da iniciativa de um estudo de caso, tendo como objeto a empresa SC Transportes. Na elaboração do diagnóstico organizacional, verificou-se na análise interna, a gestão administrativa como o departamento que demanda maiores RC: 84581

Disponível em: https://www.nucleodoconhecimento.com.br/administracao/empresa-sctransportes 
cuidados, no sentido rever, reformular e implementar estratégias que tornem a empresa mais competitiva e permitam seu crescimento.

Diante do exposto, o objetivo geral foi buscar a compreensão de como a empresa em estudo poderia beneficiar-se da adoção e implementação de novas estratégias em sua gestão administrativa. Pois, constata-se que o objetivo foi alcançado, uma vez que, efetivamente o estudo conceitual de cada ação de melhoria proposta evidenciou os benefícios provenientes de sua aplicação.

O primeiro objetivo específico estabelecido foi identificar as melhores práticas utilizadas na motivação e comunicação no âmbito interno das organizações. Nesse aspecto, considera-se que o objetivo foi atendido, tendo como ponto de partida a implantação da gestão orientada a resultados e, a partir daí estabelecer políticas que visam reconhecimento aos colaboradores. E como estratégia, nesse âmbito, pode-se citar o plano de capacitação e desenvolvimento e o plano de incentivos e bonificação.

O segundo objetivo específico foi analisar quais dessas práticas se adequam a empresa estudada. Constatou-se como objetivo atendido, já que diante das informações provenientes do diagnóstico organizacional, nenhum obstáculo que impossibilitasse a aplicação das alternativas sugeridas foi identificado, estando a empresa apta a implementar as ações elencadas neste trabalho.

O terceiro objetivo específico definido foi planejar ações para implementar as estratégias de gestão administrativa junto aos colaboradores. Este objetivo foi alcançado com a utilização da ferramenta de planejamento $5 \mathrm{~W} 2 \mathrm{H}$ que permitiu o detalhamento de cada ação sugerida por meio da aplicação de perguntas-chave acerca do problema, mostrando-se satisfatória para efetivar esta etapa do estudo.

Em face da problemática encontrada, considera-se que, o modelo de gestão proposto, juntamente com instalação de ferramentas de comunicação interna, e a estruturação de programas e planos de incentivo a colaboradores - constituem soluções eficientes.

RC: 84581

Disponível em: https://www.nucleodoconhecimento.com.br/administracao/empresa-sctransportes 
Entretanto, e por fim, recomenda-se como trabalho futuro a aplicação de um estudo mais abrangente das filiais em razão das limitações financeiras e geográficas.

\section{REFERÊNCIAS}

AQUINO, Katy Ann de Matos. Planejamento Estratégico: o desafio de uma nova cultura organizacional no Setor Público. 2016. 139 f. Dissertação (Mestrado em Contabilidade e Controladoria) - Universidade Federal do Amazonas, Manaus, 2016.

BERGUE, Sandro Trescastro. Comportamento organizacional. 03 . ed. Florianópolis: Departamento de Ciências da Administração / UFSC; [Brasília]: CAPES: UAB, 2014.

CAMACHO, Marcelo. Gestão Estratégica de Pessoas. 01. ed. Rio de Janeiro: SESES, 2016.

CANABRAVA, Tomasina; VIEIRA, Onízia de Fátima Assunção. Treinamento \& desenvolvimento para empresas que aprendem. 01. ed. Distrito Federal: Senac, 2014.

CHIAVENATO, Idalberto; SAPIRO, Arão. Planejamento estratégico: da intenção aos resultados. 04. ed. São Paulo: Atlas, 2020.

Gestão de pessoas: o novo papel dos recursos humanos nas organizações. 04. ed. Barueri: Manole, 2014.

DAMBI, Jorge Francisco. Estilos de liderança, motivação e sistemas de recompensas para a melhoria da performance das PME's. 2018. 122 f. Dissertação (Mestrado em Ciências Empresariais) - Universidade Fernando Pessoa, Porto, 2018.

DUTRA, Ademar. Gestão estratégica de pessoas. 2. ed. Palhoça: UnisulVirtual, 2014.

Disponível

em: 
$<$ https://www.uaberta.unisul.br/repositorio/recurso/14690/pdf/gestao_estrategica_de_ pessoas.pdf.>. Acesso em: 10 mar. 2021.

DREWS, Gustavo Arno et al. Estratégias de gestão de pessoas. 01. ed. ljuí: Unijuí, 2012.

$\mathrm{KUNSCH}$, Margarida Maria Krohling. As dimensões humana, instrumental e estratégica da Comunicação Organizacional: recorte de um estudo aplicado no seguimento corporativo. Intercom - RBCC. São Paulo, v.35, n.2 p. 267 - 289, jul./dez. 2012.

LANGHI, Celi. Treinamento e desenvolvimento: acompanhamento e movimentação de pessoas. 01. ed. São Paulo: Senac, 2019.

MATOS, Gustavo Gomes de. Comunicação empresarial: sem complicação. 03. ed. São Paulo: Manole, 2014.

MELO, Luiz Roberto Dias de. Comunicação empresarial. 02. ed. Curitiba: IESDE Brasil, 2018.

NASCIMENTO, Renato Souza do. Comunicação empresarial integrada. 01. ed. Rio de Janeiro: SESES, 2016.

NEVES, R. de C. Comunicação empresarial integrada: como gerenciar imagem, questões públicas, comunicação simbólica, crises empresariais. 03. Ed. Rio de Janeiro: Mauad, 2015.

OLBRZYMEK, Juliana Regiani. Comportamento, clima e cultura organizacional. 01. ed. Indaial: UNIASSELVI, 2017.

PALUDO, Augustinho Vicente. Administração pública. 03. ed. São Paulo: Método, 2016. 
PEREIRA, Adriana Soares et al. Metodologia do trabalho científico. 01. Ed. Santa Maria: UAB/ NTE/ UFSM, 2018.

PORPINO, Gustavo; DE STEFANI, Emerson. O caso do PAC Embrapa: requisitos de uma gestão orientada para resultados no setor público. Rev. Adm. Pública, Rio de Janeiro, v. 48, n. 2, p. 343-366, abr. 2014. Disponível em: < http://www.scielo.br/scielo.php?script=sci_arttext\&pid=S0034-76122014000200004\& Ing=en\&nrm=iso $>$. Acesso em 11 mar. 2021.

SILVA, Antônio João Hocayen da. Metodologia de Pesquisa: Conceitos Gerais. 01. ed. Guarapuava: Unicentro, 2014.

SILVA, Victor Andrei da. Comunicação Empresarial e Negociação. 01. ed. Maringá: Unicesumar, 2018.

ZANELLA, Liane Carly Hermes. Metodologia de pesquisa. 02. ed. Florianópolis: Departamento de Ciências da Administração/UFSC, 2013.

Enviado: Março, 2021.

Aprovado: Maio, 2021. 